\title{
Original
}

\section{A healing period increases mini-implant stability in growing rats}

\author{
Shinya Yano'), Mitsuru Motoyoshi1,2), Mizuki Inaba1), Saori Yano1), \\ Hiroyuki Takenouchi1), Seil Son'3), Yoshinori Arai4), and Noriyoshi Shimizu1,2) \\ 1)Department of Orthodontics, Nihon University School of Dentistry, Tokyo, Japan \\ 2)Division of Clinical Research, Dental Research Center, Nihon University School of Dentistry, Tokyo, Japan \\ 3)Private Practice, Seoul, Korea \\ 4)Nihon University School of Dentistry, Tokyo, Japan
}

(Received December 16, 2013; Accepted March 5, 2014)

\begin{abstract}
We assessed the stability of orthodontic mini-implants in young rats. Male rats with mean ages of 6 weeks $(n=16)$ and 20 weeks $(n=16)$ were divided into four groups $(n=8$ each). In the 6- and 20-week immediate-loading groups, immediately after placement, mini-implants were exposed to an experimental traction force for 2 weeks. In the 6- and 20-week healing groups, the force was applied for 2 weeks after a 6-week healing period. Right tibiae served as the test limbs and the left tibiae as controls. A Periotest device was used to measure mini-implant mobility after traction, and Tukey's test was used to compare Periotest values among groups. The results showed significantly greater mobility in the 6-week immediate-loading group than in the $\mathbf{2 0}$-week immediate-loading and 6- and 20-week healing groups, and significantly less mobility in the 6-week healing group than in the 20-week immediate-loading group $(P<$ 0.05). Mini-implants were stable during the healing period. The results indicate that mini-implants can be used for orthodontic anchorage in juvenile patients if the duration of healing is sufficient.
\end{abstract}

(J Oral Sci 56, 113-118, 2014)

Correspondence to Dr. Mitsuru Motoyoshi, Department of Orthodontics, Nihon University School of Dentistry, 1-8-13 Kanda-Surugadai, Chiyoda-ku, Tokyo 101-8310, Japan Fax: +81-3-3219-8365

E-mail: motoyoshi.mitsuru@nihon-u.ac.jp

doi.org/10.2334/josnusd.56.113

DN/JST.JSTAGE/josnusd/56.113
Keywords: mini-implant; healing period; mobility test; growing rats.

\section{Introduction}

In orthodontic treatment, mini-implants placed in alveolar bone have been used as skeletal anchorage and have improved treatment outcomes (1-4). Mini-implants that are able to endure immediate loading have been developed and used clinically $(5,6)$. However, these mini-implants sometimes show mobility and failure during orthodontic treatment $(7,8)$, especially in adolescents, although mini-implants are often required in such patients (9).

The success rate for immediate loading of miniimplants in adolescent patients was $60-80 \%$ in one study (10). The stability of mini-implants is related to clinical factors such as oral hygiene (11), the degree of inflammation accompanying local irritation, excessive orthodontic force (7), the design and shape of the screw thread (12), and the proximity of the mini-implant to the roots of adjacent teeth (13). However, low success rates are most likely related to active bone metabolism during growth and to the low rate of bone maturation. Despite the increasing number of clinical $(7,8,14-19)$ and animal (20-23) studies of mini-implants, doubts remain regarding optimal placement locations and techniques, appropriate force levels, the need for a healing period (vs immediate loading), and the effects of patient age.

Motoyoshi et al. (6) suggested that orthodontic miniimplants require a latent period to increase the success rate in adolescent patients; however, they did not perform 


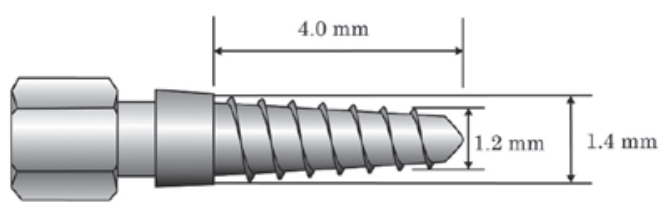

Fig. 1 The mini-implant (diameter $=1.4 \mathrm{~mm}[$ spearhead $=1.2 \mathrm{~mm}]$, length $=4.0 \mathrm{~mm}$ ) used in this study.

Test group ( right tibia, $n=32$ )

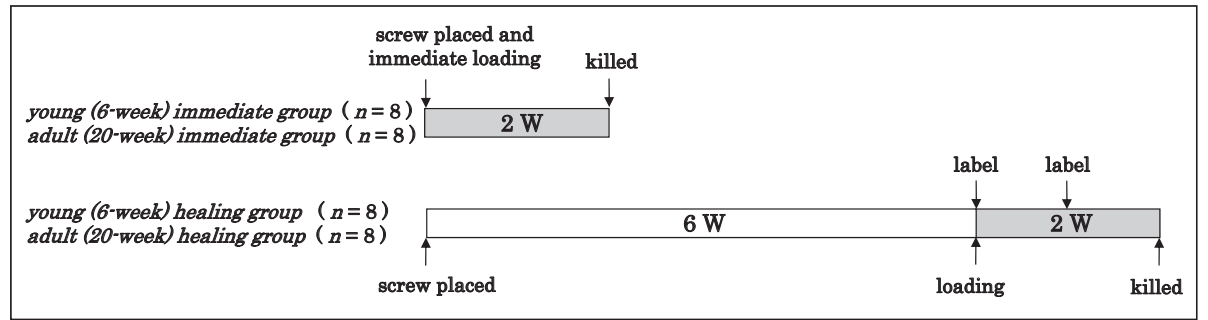

Control group ( left tibia, $n=32$ )

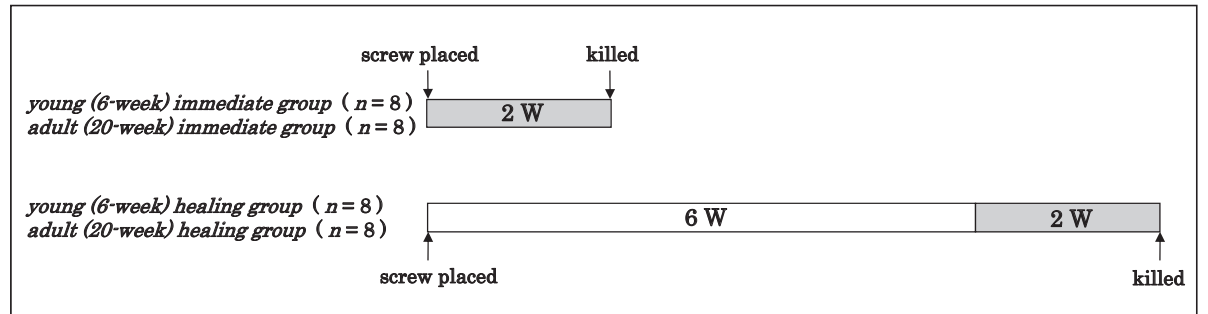

Fig. 2 Flowchart showing the protocol for the test and control groups. The right tibia of each rat was used as the test limb. The young (6-week) and adult (20-week) immediate-loading groups were exposed to an experimental traction force for 2 weeks immediately after placement. In the young and adult healing groups, force was applied for 2 weeks after a 6 -week healing period. The left tibiae in each group were not exposed to any experimental force during the experimental period ( 2 or 8 weeks). The number of rats studied is shown in parentheses.

objective assessments of mini-implant stability.

According to Olivé et al. (20), Inaba et al. (24), and Uemura et al. (25), the mobility test is an objective and straightforward method of evaluating the success of implantation. In particular, mobility is thought to be an appropriate index of primary implant stability, as a previous study (24) found a strong correlation between the implant-bone contact ratio and an index of mobility.

We therefore used mobility measurements to assess the stability of mini-implants and evaluate the feasibility of immediate mini-implant loading in adolescent patients. Specifically, we examined differences in the stability of mini-implants according to age and healing period in immature and mature rats. In addition, computed tomography (CT) was used to evaluate bone growth and maturation in the rats.

\section{Materials and Methods}

First, a pilot study using microfocus CT (mCT; Rigaku, Tokyo, Japan) was performed. CT images of tibiae from three male Wistar rats were obtained at $6,8,12,14,20$, 22,26 , and 28 weeks of age. We compared cortical bone thickness (BT), bone volume (BV), and bone density (BD) in young and mature rats.

$\mathrm{BT}, \mathrm{BV}$, and $\mathrm{BD}$ values showed a tendency to increase until 20 weeks of age, when they were highest. We estimated that a 6-week-old rat corresponded to an approximately 10 -year-old human, and a 20 -week-old rat to an approximately 20 -year-old human. Therefore, we used 6- and 20-week-old rats in this research. In addition, because $\mathrm{BT}, \mathrm{BV}$, and $\mathrm{BD}$ values did not differ between the right and left tibiae, the right tibia of each rat served as the test limb and the left tibia as the control limb.

In total, 32 male Wistar rats were prepared in order to assess mini-implant stability: 16 young rats (age, 6 weeks; mean body weight, $180 \pm 20 \mathrm{~g}$ ) and 16 adult rats (age, 20 weeks; mean body weight, $500 \pm 20 \mathrm{~g}$ ). Miniimplants $(n=64$; diameter $=1.4 \mathrm{~mm}$ [spearhead $=1.2$ $\mathrm{mm}]$, length $=4.0 \mathrm{~mm}$; Fig. 1) were placed into all rat tibiae, and a nickel titanium (Ni-Ti) coil spring was used to apply a $2-\mathrm{N}$ traction force. The animals were divided into an immediate-loading group (immediate group) and a healing group, which was subjected to loading after a 6-week healing period. The immediate and healing 


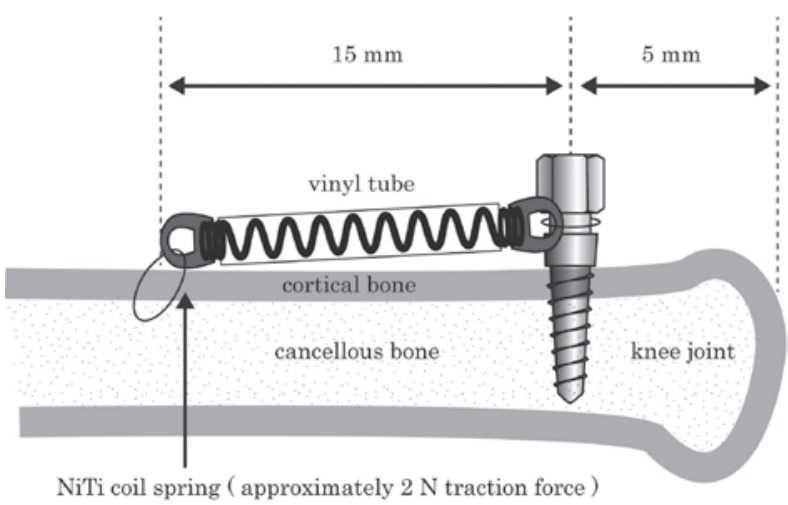

Fig. 3 Insertion position of mini-implants and method of loading. Holes were prepared at points 5.0 and $20.0 \mathrm{~mm}$ inferior to the knee joint, to fix a closed nickel-titanium coil spring for application of traction force $(2 \mathrm{~N})$.

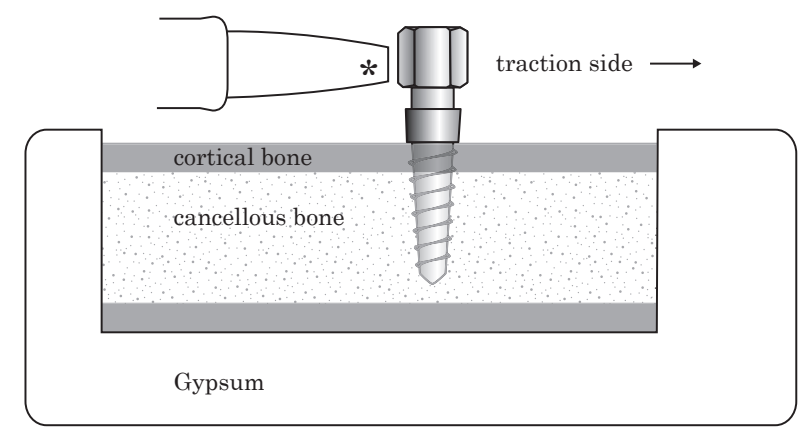

Fig. 4 Use of the Periotest device for mobility measurement. All mini-implants were covered with gypsum to facilitate measurement.

*tip of the Periotest handpiece

groups were each subdivided into two subgroups of young (6-week) and adult (20-week) rats. The left tibia of each rat was used as a control and was not exposed to any experimental force during the experimental period (Fig. 2).

All experiments were approved by the Animal Experimentation Committee of Nihon University School of Dentistry (AP10D018).

\section{Surgical procedure and force application}

After anesthesia with an intraperitoneal injection of sodium pentobarbitone (Nembutal, $100 \mathrm{mg} / \mathrm{kg}$ body weight; Dainippon Pharmaceutical Co., Ltd., Osaka, Japan), an incision was made along the tibial crest, and the surface of the tibia was exposed. A hole was then prepared at the point $5.0 \mathrm{~mm}$ inferior to the knee joint, using a bone drill with a diameter of $1.0 \mathrm{~mm}$ and length of $3.0 \mathrm{~mm}$ (Dentsply-Sankin Co., Ltd., Tokyo, Japan) placed perpendicular to the bone surface under physiological saline flow. A mini-implant was inserted into each hole using a hand driver, and a hole (1.0-mm diameter) was formed at a point $20.0 \mathrm{~mm}$ inferior to the knee joint in order to fix a closed Ni-Ti coil spring (Tomy International Co., Ltd., Tokyo, Japan) for application of traction force $(\sim 2 \mathrm{~N})$ for 2 weeks (Fig. 3). To prevent infection after surgery, tetracycline CMC paste (tetracycline hydrochloride paste; Showa Yakuhin Kako Co., Ltd., Tokyo, Japan) was applied to the surgical site.

The young and adult immediate groups ( $n=8$ each) underwent experimental traction for 2 weeks immediately after placement. In the young and adult healing groups ( $n=8$ each), force was applied for 2 weeks after a 6-week healing period (Fig. 2), according to the protocol of Ohmae et al. (22). The right tibia of each rat was used as the test limb and the left tibia was used as the control limb, which was not exposed to any experimental force during the experimental period ( 2 or 8 weeks).

\section{Measurement of mobility}

At the end of the experiment, the rats were killed with pentobarbital, and the Ni-Ti coil springs were removed from the mini-implants. The bodies of all specimens, excluding the placement site, were covered with gypsum to facilitate measurement of mobility with a Periotest device (Siemens AG, Bensheim, Germany; Fig. 4), as detailed in our previous study (25). The tapping head of the Periotest device has a pressure-sensitive tip that records duration of contact with the implant. The looser the mini-implant, the longer the contact time and the higher the Periotest value (PTV). Conversely, stable mini-implants yield short contact times, which results in lower PTVs. Rigid fixation of the specimen is extremely important for the accuracy of Periotest measurements. Because the specimens were small and fixation was difficult, especially for specimens from young rats, portions not subjected to measurement were covered with gypsum. PTVs were determined for each miniimplant. Each measurement was repeated five times, and the average was used in the analysis. All measurements were performed by the same examiner, to eliminate interexaminer error. Tukey's test was used to compare PTVs among groups. The SPSS statistical software package (ver. 10.0 for Windows; SPSS Inc., Chicago, IL, USA) was used for all the analyses.

\section{Histological examination}

Calcein is a fluorescent label that binds to calcium and is incorporated into growing calcium carbonate crystals (26). Calcein labeling makes it possible to determine the onset time and location of osteogenesis. Two weeks before the rats were killed, they were given subcutaneous 


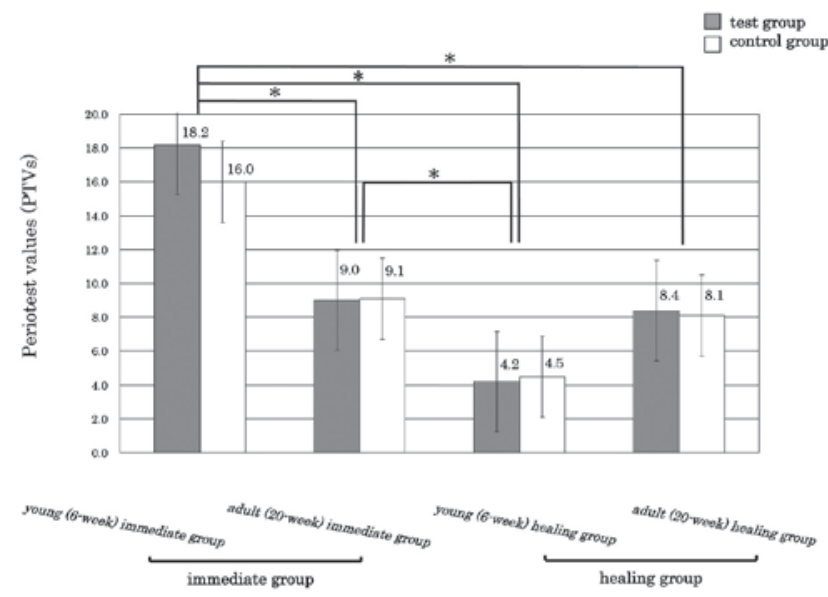

Fig. 5 Comparison of Periotest values in each group. No significant difference was observed between the test and control limbs in any group. *: $P<0.05$.

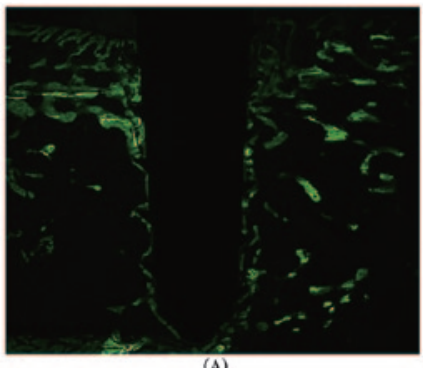

(A)
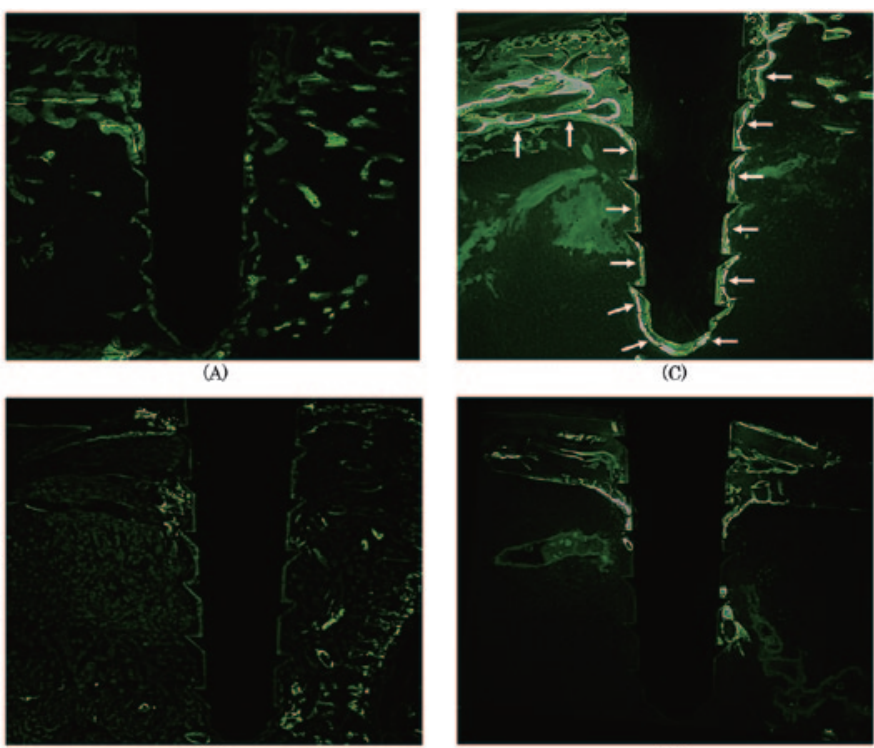

(B)

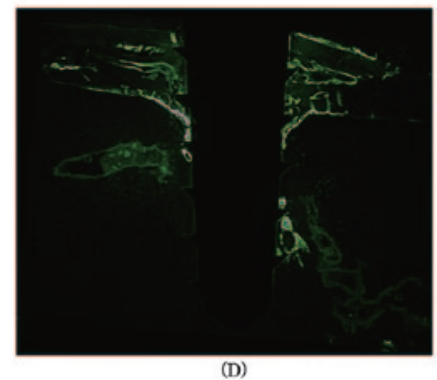

Fig. 6 Representative fluorescence microscopic images of the area around the mini-implant in the test groups. (A) Young (6-week) immediate-loading group, (B) Adult (20-week) immediate-loading group, (C) Young healing group, (D) Adult healing group.

new bone on the mini-implant surface.

injections of calcein $(10 \mathrm{mg} / \mathrm{kg}$; Wako Pure Chemical Industries, Ltd., Osaka, Japan) to label the tissues for fluorescence microscopy (Keyence Corporation, Tokyo, Japan). Labeling was performed twice, with a 1-week interval.

\section{Results}

\section{Mobility of mini-implants}

PTVs are shown in Fig. 5. In the test and control groups, PTVs were significantly higher in the young (6-week) immediate group than in the adult (20-week) immediate group (test: 2.02-fold, control: 1.76-fold; $P<0.05$ ), the young healing group (test: 4.33 -fold, control: 3.56 -fold; $P<0.05$ ), and the adult healing group (test: 2.17 -fold, control: 1.98 -fold; $P<0.05$ ). PTVs were significantly lower in the young healing group than in the adult immediate group (test: 0.47 -fold, control: 0.49 -fold; $P<0.05$ ). PTVs did not differ significantly between the test and control groups.

\section{Fluorescence microscopic observation}

Representative fluorescence microscopic images of the areas near the mini-implants are shown in Fig. 6. Calcein regions show new bone laid down near the mini-implant at 2 weeks before the rats were euthanized. As compared with the other test groups, greater calcein labeling (white arrows) was seen in the cortical bone in the young healing group (test group C). This was followed by formation of

\section{Discussion}

The mobility test is an objective, straightforward method of evaluating implantation success $(20,24,25)$. Uemura et al. (25) drilled pilot holes of various diameters in rat tibiae, inserted a mini-implant (1.2-mm diameter) in each hole, and applied an experimental traction force for 3 weeks. They used a Periotest device to assess all mini-implants before and after traction and found that mobility measurements were useful for predicting miniimplant outcomes. In addition, Inaba et al. (24) found a strong correlation between the implant-bone contact ratio and PTVs $(\mathrm{r}=0.590, P<0.05)$. Thus, PTVs are an appropriate index of primary implant stability. Inserting mini-implants into the jaw bone of 6-week-old rats is difficult. Although the patterns of bone formation differ between the jaw bone and tibial bone, a method involving the use of tibial bone was developed, and its reliability and stability were confirmed $(5,25)$. We thus used tibial bones rather than jaw bones in the present study.

Previous reports (27-30) described insertion of implants in growing animals. Odman et al. (27) placed osseointegrated implants in six growing pigs in areas where different patterns of dentoalveolar development were expected. In their experimental model, total fixture loss was observed in 6 of 20 originally installed implants. Asscherickx et al. (29) inserted mini-implants in the 
median palatal sutures of growing dogs. On day 42 , three of four posterior palatal implants and one of four anterior palatal implants were lost. The results of the present study support the findings of Odman et al.(27) and Asscherickx et al. (29), who reported a low success rate in growing animals. PTVs were lower in the present groups with a fixed healing period than in the young immediate group, and the 6-week healing period improved mini-implant stability.

In a clinical study, Miyawaki et al. (7) inserted miniimplants in 51 patients with a mean age of $21.8 \pm 1.8$ years. They found a slightly lower success rate in patients younger than 20 years $(80 \%)$ than in those older than 20 years $(85-88 \%)$, but the difference was not significant. Garfinkle et al. (10) placed mini-implants in the buccal alveolar bone of 13 patients (eight females, five males; average age, 14 years 10 months). They reported no significant difference between the success rates of immediately-loaded mini-implants $(80.0 \%)$ and those for which loading was delayed $(81.0 \%)$. However, the combined success rate for loaded mini-implants $(80.5 \%)$ was significantly higher than that for unloaded miniimplants $(61.0 \%)$. In the present study, PTVs did not significantly differ between mini-implants subjected to a traction force (test group) and those that were not (control group). It may be that traction force applied within a certain range $(\sim 2 \mathrm{~N})$ has little impact on mini-implant stability. The difference between the results of this study and those reported by Miyawaki et al. (7) and Garfinkle et al. (10) could be due to differences in specimen materials and age distribution.

Motoyoshi et al. (6) placed mini-implants in 30 adolescent and 27 adult orthodontic patients. The success rate was $63.8 \%$ in early-loaded adolescents, $97.2 \%$ in late-loaded adolescents, and $91.9 \%$ in adults. These results indicate that the healing period improved miniimplant stability, thereby increasing the success rate. However, these studies examined mini-implant survival rate without directly evaluating mobility. In the present study, PTVs were evaluated to examine mini-implant stability. The PTV was significantly higher $(P<0.05)$ in the young immediate group than in the other groups. However, the PTV of the young healing group was significantly improved $(P<0.05)$. Furthermore, the PTV was significantly lower $(P<0.05)$ in the young healing group (4.2 \pm 1.9$)$ than in the adult immediate group (8.4 $\pm 2.4)$. Our PTV measurements are consistent with the results of Motoyoshi et al. (6).

Fluorescent microscopic images are also useful for confirming bone formation in the area surrounding implants (22,23,30-32). Deguchi et al. (23) used fluo- rescent and polarized microscopic to evaluate growing dogs and found that mini-implants were able to function as rigid osseous anchors during orthodontic loading for 3 months. In our microscopic examination, identification of new bone in the images was difficult; however, active bone formation surrounding mini-implants was likely present in the young healing group.

In both the present and previous studies $(23,33)$, PTV was significantly lower $(P<0.05)$ in growing rats allowed a 6-week healing period. This reduction may have been caused by bone formation during growth, as active bone formation might increase mini-implant stability. It is thought that the amount of bone growth is greatest at about age 5-12 years in humans and that bone growth becomes more gradual after about age 20 years. In our comparison of the ages of rats and humans, we estimated that a 6-week-old rat corresponds to an approximately 10 -year-old human and that a 20 -week-old rat corresponds to an approximately 20 -year-old human.

The PTV was significantly higher $(P<0.05)$ in the young immediate group than in the young healing group. Thus, in growing rats of the same age mini-implants were more stable after a healing period than with immediate loading. This improvement in stability is probably related to bone maturation due to growth and bone healing.

In the present study, PTVs were significantly higher in the young immediate group than in the other groups. In contrast, PTVs were significantly lower in the young healing group than in the adult immediate group. In adolescent patients, mini-implants may be useful as orthodontic anchors but should be placed before the start of orthodontic treatment, to provide a healing period of several months. The healing period in humans and animals is probably not comparable, but our data provide preliminary clinical evidence of the importance of such a period. These results may be useful in developing clinical indices for the timing of orthodontic mini-implant placement in adolescents.

\section{Acknowledgments}

This study was supported by the Sato Fund, a grant from the Dental Research Center, Nihon University School of Dentistry, and a Grant-in-Aid for Scientific Research (No. 24593111).

\section{References}

1. Park HS, Kwon TG, Kwon OW (2004) Treatment of open bite with microscrew implant anchorage. Am J Orthod Dentofacial Orthop 126, 627-636.

2. Chung K, Kim SH, Kook Y (2005) C-orthodontic microimplant for distalization of mandibular dentition in Class III correction. Angle Orthod 75, 119-128. 
3. Ohnishi H, Yagi T, Yasuda Y, Takada K (2005) A miniimplant for orthodontic anchorage in a deep overbite case. Angle Orthod 75, 444-452.

4. Motoyoshi M (2011) Clinical indices for orthodontic miniimplants. J Oral Sci 53, 407-412.

5. Yano S, Motoyoshi M, Uemura M, Ono A, Shimizu N (2006) Tapered orthodontic miniscrews induce bone-screw cohesion following immediate loading. Eur J Orthod 28, 541-546.

6. Motoyoshi M, Matsuoka M, Shimizu N (2007) Application of orthodontic mini-implants in adolescents. Int J Oral Maxillofac Surg 36, 695-699.

7. Miyawaki S, Koyama I, Inoue M, Mishima K, Sugahara T, Takano-Yamamoto T (2003) Factors associated with the stability of titanium screws placed in the posterior region for orthodontic anchorage. Am J Orthod Dentofacial Orthop 124, 373-378.

8. Cheng SJ, Tseng IY, Lee JJ, Kok SH (2004) A prospective study of the risk factors associated with failure of miniimplants used for orthodontic anchorage. Int J Oral Maxillofac Implants 19, 100-106.

9. Park HS, Lee SK, Kwon OW (2005) Group distal movement of teeth using microscrew implant anchorage. Angle Orthod 75, 602-609.

10. Garfinkle JS, Cunningham LL Jr, Beeman CS, Kluemper GT, Hicks EP, Kim MO (2008) Evaluation of orthodontic mini-implant anchorage in premolar extraction therapy in adolescents. Am J Orthod Dentofacial Orthop 133, 642-653.

11. Hoste S, Vercruyssen M, Quirynen M, Willems G (2008) Risk factors and indications of orthodontic temporary anchorage devices: a literature review. Aust Orthod J 24, 140-148.

12. Holmgren EP, Seckinger RJ, Kilgren LM, Mante F (1998) Evaluating parameters of osseointegrated dental implants using finite element analysis--a two-dimensional comparative study examining the effects of implant diameter, implant shape, and load direction. J Oral Implantol 24, 80-88.

13. Kuroda S, Yamada K, Deguchi T, Hashimoto T, Kyung HM, Takano-Yamamoto T (2007) Root proximity is a major factor for screw failure in orthodontic anchorage. Am J Orthod Dentofacial Orthop 131, S68-73.

14. Fritz U, Ehmer A, Diedrich P (2004) Clinical suitability of titanium microscrews for orthodontic anchorage-preliminary experiences. J Orofac Orthop 65, 410-418.

15. Liou EJ, Pai BC, Lin JC (2004) Do miniscrews remain stationary under orthodontic forces? Am J Orthod Dentofacial Orthop 126, 42-47.

16. Gelgör IE, Büyükyilmaz T, Karaman AI, Dolanmaz D, Kalayci A (2004) Intraosseous screw-supported upper molar distalization. Angle Orthod 74, 838-850.

17. Herman RJ, Currier GF, Miyake A (2006) Mini-implant anchorage for maxillary canine retraction: a pilot study. Am J Orthod Dentofacial Orthop 130, 228-235.

18. Park HS, Jeong SH, Kwon OW (2006) Factors affecting the clinical success of screw implants used as orthodontic anchorage. Am J Orthod Dentofacial Orthop 130, 18-25.
19. Kuroda S, Sugawara Y, Deguchi T, Kyung HM, TakanoYamamoto T (2007) Clinical use of miniscrew implants as orthodontic anchorage: success rates and postoperative discomfort. Am J Orthod Dentofacial Orthop 131, 9-15.

20. Olivé J, Aparicio C (1990) Periotest method as a measure of osseointegrated oral implant stability. Int J Oral Maxillofac Implants 5, 390-400.

21. Melsen B, Costa A (2000) Immediate loading of implants used for orthodontic anchorage. Clin Orthod Res 3, 23-28.

22. Ohmae M, Saito S, Morohashi T, Seki K, Qu H, Kanomi R et al. (2001) A clinical and histological evaluation of titanium mini-implants as anchors for orthodontic intrusion in the beagle dog. Am J Orthod Dentofacial Orthop 119, 489-497.

23. Deguchi T, Takano-Yamamoto T, Kanomi R, Hartsfield JK Jr, Roberts WE, Garetto LP (2003) The use of small titanium screws for orthodontic anchorage. J Dent Res 82, 377-381.

24. Inaba M (2009) Evaluation of primary stability of inclined orthodontic mini-implants. J Oral Sci 51, 347-353.

25. Uemura M, Motoyoshi M, Yano S, Sakaguchi M, Igarashi Y, Shimizu N (2012) Orthodontic mini-implant stability and the ratio of pilot hole implant diameter. Eur J Orthod 34, 52-56.

26. Tambutté E, Tambutté S, Segonds N, Zoccola D, Venn A, Erez J et al. (2012) Calcein labelling and electrophysiology: insights on coral tissue permeability and calcification. Proc Biol Sci 279, 19-27.

27. Odman J, Gröndahl K, Lekholm U, Thilander B (1991) The effect of osseointegrated implants on the dento-alveolar development. A clinical and radiographic study in growing pigs. Eur J Orthod 13, 279-286.

28. Thilander B, Odman J, Gröndahl K, Lekholm U (1992) Aspects on osseointegrated implants inserted in growing jaws. A biometric and radiographic study in the young pig. Eur J Orthod 14, 99-109.

29. Asscherickx K, Hanssens JL, Wehrbein H, Sabzevar MM (2005) Orthodontic anchorage implants inserted in the median palatal suture and normal transverse maxillary growth in growing dogs: a biometric and radiographic study. Angle Orthod 75, 826-831.

30. Vande Vannet B, Sabzevar MM, Wehrbein H, Asscherickx K (2007) Osseointegration of miniscrews: a histomorphometric evaluation. Eur J Orthod 29, 437-442.

31. Büchter A, Wiechmann D, Gaertner C, Hendrik M, Vogeler M, Wiesmann HP et al. (2006) Load-related bone modeling at the interface of orthodontic micro-implants. Clin Oral Implants Res 17, 714-722.

32. Chen YH, Chang HH, Chen YJ, Lee D, Chiang HH, Jane Yao CC (2008) Root contact during insertion of miniscrews for orthodontic anchorage increases the failure rate: an animal study. Clin Oral Implant Res 19, 99-106.

33. Motoyoshi M, Yoshida T, Ono A, Shimizu N (2007) Effect of cortical bone thickness and implant placement torque on stability of orthodontic mini-implants. Int J Oral Maxillofac Implants 22, 779-784. 